\title{
ANALISIS KETIDAKPASTIAN PENGUKURAN KEKUATAN TARIK DAN ELONGASI SPESIMEN SS304 BERBENTUK RING
}

\author{
Sri Ismarwanti', Jan Setiawan', Maman Kartaman Ajiriyanto', Rohmad Sigit ${ }^{1}$ \\ ${ }^{1}$ Pusat Riset dan Teknologi Bahan Bakar Nuklir - BRIN \\ Kawasan PUSPIPTEK Serpong Gd. 20 Tangerang Selatan, Banten 15314 \\ e-mail: srii004@brin.go.id; isma@batan.go.id
}

(Naskah diterima: 04-10-2021, Naskah direvisi: 15-10-2021, Naskah disetujui: 26-10-2021)

\begin{abstract}
ABSTRAK
ANALISIS KETIDAKPASTIAN PENGUKURAN KEKUATAN TARIK DAN ELONGASISPESIMEN SS304 BERBENTUK RING. Ketidakpastian adalah tolok ukur dari kehandalan suatu pengukuran. Salah satu pendekatan analisa ketidakpastian yang banyak digunakan adalah dengan menggunakan Guide to the expression of uncertainty in measurement (GUM). Langkah-langkah untuk menganalisa ketidakpastian dari suatu pengukuran telah dijelaskan secara rinci oleh pendekatan GUM. Analisa ketidakpastian dilakukan pada pengujian tarik untuk mengetahui ketertelusuran data yang diperoleh. Pengujian tarik menghasilkan data berupa kekuatan tarik dan elongasi dari material uji. Kekuatan tarik adalah besaran yang melibatkan besaran gaya dan panjang. Elongasi adalah penambahan panjang saat dilakukan penarikan. Kekuatan tarik pada sampel berbentuk ring akan dipengaruhi oleh luas penampang pada kedua belah sisi ring ketika diberikan tegangan tarik. Sehingga untuk menentukan ketidakpastian pengujian tarik akan memerlukan analisa terhadap penyumbang ketidakpastian. Makalah ini memberikan penjelasan bagaimana cara untuk menganalisa ketidakpastian pengukuran kekuatan tarik dan elongasi pada sampel berbentuk ring. Selain itu juga akan diperoleh nilai ketidakpastian pengukuran kekuatan tarik dan elongasi SS304 berbentuk ring. Dari pengujian yang dilakukan dapat diketahui bahwa kekuatan tarik ring SS304 rata-rata adalah 631,070 $\pm 26,976 \mathrm{Nmm}^{-2}$ dengan ketidakpastian diperluas sebesar $50,451 \mathrm{Nmm}^{-2}$ pada tingkat kepercayaan $95 \%$. Selain itu pada tingkat kepercayaan yang sama diperoleh hasil elongasi ring SS304 rata-rata $18,681 \% \pm 2,425 \%$ dengan ketidakpastian diperluas sebesar $2,867 \%$. Keberulangan data atau repeatability menjadi penyumbang terbesar terhadap ketidakpastian pengukuran kekuatan tarik dan elongasi ring SS304.
\end{abstract}

Kata kunci: Ketidakpastian, GUM, kekuatan tarik, elongasi, ring SS304. 


\begin{abstract}
ANALYSIS OF UNCERTAINTY IN THE MEASUREMENT OF TENSILE STRENGTH AND ELONGATION OF RING-SHAPED SS304 TEST SPECIMENS. Uncertainty is a measure of the reliability of a measurement. One of the widely used uncertainty analysis approaches is the Guide to the expression of uncertainty in measurement (GUM). The steps for analyzing the uncertainty of a measurement have been described in detail by the GUM approach. Uncertainty analysis was carried out on tensile testing to determine the traceability of the data obtained. Tensile testing produces data in the form of tensile strength and elongation of the test material. Tensile strength is a quantity that involves the magnitude of the force and length. Elongation is the increase in length when pulling. The tensile strength of the ring-shaped sample will be affected by the cross-sectional area on both sides of the ring when a tensile stress is applied. So, to determine the uncertainty of the tensile test, an analysis of the contributors to the uncertainty is required. This paper provides an explanation of how to analyze the uncertainty of the measurement of tensile strength and elongation in a ring-shaped sample. In addition, the value of the uncertainty in the measurement of tensile strength and elongation of SS304 (in the form of a ring) will also be presented. The test results show that the average tensile strength of SS304 rings is $631.070 \pm 26.976 \mathrm{Nmm}^{-2}$ with an expanded uncertainty of $50.451 \mathrm{Nmm}^{-2}$ at a $95 \%$ confidence level. In addition, at the same level of confidence, the average SS304 ring elongation result is $18.681 \% \pm 2.425 \%$ with an expanded uncertainty of $2.867 \%$. Data repetition or repeatability is the biggest contributor to the uncertainty in measuring the tensile strength and elongation of the SS304 ring.
\end{abstract}

Keywords: Uncertainty, GUM, tensile strength, elongation, SS304 ring 
Analisis Ketidakpastian Pengukuran Kekuatan Tarik dan Elongasi

Spesimen SS304 Berbentuk Ring

(Sri Ismarwanti, Jan Setiawan, Maman Kartaman Ajiriyanto, Rohmad Sigit)

\section{PENDAHULUAN}

Ketidakpastian

pengukuran

menggambarkan hasil dan keandalan dari pengukuran yang telah dilakukan. Suatu pengujian jika mempunyai rentang ketidakpastian kecil maka hasil pengujiannya menjadi lebih akurat dan tepat. Ketidakpastian pengukuran dapat dianalisa dengan menggunakan pendekatan GUM (Guide to the expression of uncertainty in measurement). Pendekatan GUM adalah metode konvensional yang banyak digunakan untuk menentukan ketidakpastian dengan persamaan yang sederhana[1]-[3]. Metode GUM dapat digunakan untuk menentukan ketidakpastian secara tidak langsung atau yang diturunkan dari persamaan. Dengan menggunakan pendekatan GUM sumber ketidakpastian dibedakan menjadi dua klasifikasi yaitu sumber ketidakpastian tipe $A$ dan B. Sumber ketidakpastian tipe A adalah berasal dari pengamatan data ukur, sedangkan tipe B adalah sumber ketidakpastian yang berasal selain dari pengamatan data ukur[4]. Chen dkk, melakukan analisa ketidakpastian pengukuran untuk pengukuran pernafasan dengan menggunakan metode GUM dan metode Monte Carlo (MC), hasilnya menunjukkan bahwa kedua metode tidak berbeda jauh hingga angka dua desimal[5]. Selain itu analisa ketidakpastian untuk pengujian mekanik telah dilakukan oleh Salah dkk. Analisa dilakukan pada pengujian tegangan dan elongasi dengan membandingkan antara metode GUM, MC dan Monte Carlo Marchov Chain (MCMC). Metode MCMC memberikan ketidakpastian yang besar daripada metode MC dan GUM[6].

Kekuatan tarik maksimum atau ultimate tensile strength (UTS) atau yang lebih sering disebut kekuatan tarik adalah tegangan tarik maksimum yang dapat ditoleransi suatu material saat mengalami perpanjangan sebelum akhirnya patah. Dengan kata lain kekuatan tarik maksimum adalah batas maksimal material untuk menahan kekuatan yang diberikan tanpa menyebabkan kesalahan. Kekuatan tarik dihitung sebagai gaya per satuan luas. Gaya diperoleh dari hasil pengukuran yang direkam oleh alat uji tarik. Luas diperoleh dari pengukuran dimensi lebar dan tebal bahan. Selain kekuatan tarik, paramater penting lainnya dalam pengujian tarik uniaksial adalah elongasi yang didefinisikan sebagai perubahan panjang sebelum dan sesudah diberi beban tarik. Shamsuri dkk, telah mengimplementasikan pendekatan GUM untuk menentukan ketidakpastian pengukuran kekuatan tarik dan flexure test. Hasil penelitianya menunjukkan bahwa pendekatan GUM ini dapat diaplikasikan[7]. Dalam pengujian pasca iradiasi pengujian tarik secara tranversal diperlukan untuk mengetahui deformasi uniaxial ke arah lingkaran karena adanya efek radiasi terhadap bahan struktur dan kelongsong bahan bakar nuklir. Pengujian tarik bentuk ring sampel pasca iradiasi ini juga dikembangkan untuk mengurangi limbah radioaktif. Uji tarik ring telah dikembangkan oleh beberapa peneliti sebelumnya dengan menggunakan gauge T[8]. Optimalisasi juga pernah dilakukan oleh Nagase dkk, dengan single gauge $\mathrm{T}$ pada cincin[9] dan telah dikaji juga oleh Yoon[10]. Pada penelitian sebelumnya, uji tarik berbentuk ring ini telah dikembangkan untuk pengujian bahan bakar kelongsong pasca iradiasi di Indonesia[11]. Untuk mendapatkan ketertelusuran data maka analisa ketidakpastian pengukuran kekuatan tarik dan elongasi ring perlu dilakukan. Dalam makalah ini, analisis ketidakpastian pengukuran akan dilakukan terhadap bahan uji ring SS304. Faktor-faktor yang menyebabkan ketidakpastian akan dianalisa sehingga pada akhirnya akan diperoleh nilai ketidakpastian dari pengukuran kekuatan tarik dan elongasi ring SS304.

\section{METODOLOG}

Analisa ketidakpastian dilakukan menggunakan pendekatan GUM. Pertama adalah melakukan pengujian tarik dengan menggunakan universal testing machine (UTM) merk Shimadzu dengan modifikasi pemegang sampel untuk sampel ring. Pengujian dilakukan dengan menggunakan bahan SS304 tube yang dipreparasi berbentuk ring dengan lebar $\pm 4 \mathrm{~mm}$ sebanyak 7 buah. Laju penarikan sampel adalah $1 \mathrm{~mm} /$ menit. Pengukuran dimensi bahan uji (lebar dan tebal) dilakukan dengan menggunakan micrometer yang telah dikalibrasi. Setelah dilakukan pengujian tarik uniaksial, selanjutnya adalah menentukan sumber ketidakpastian sesuai dengan metode GUM dan menentukan persamaan ketidakpastian gabungannya. Ketidakpastian gabungan diperoleh dari beberapa langkah yang harus dilakukan yaitu menentukan sumber ketidakpastian A dan B dengan 
menggunakan diagram fishbone, kemudian menentukan model matematis untuk menghitung ketidakpastian pengukuran kekuatan tarik dan elongasinya.

\section{HASIL DAN PEMBAHASAN}

\section{a. Analisa Ketidakpastian Pengukuran} Kekutan Tarik

Ketidakpastian pengukuran kekuatan tarik dapat berasal dari beberapa sumber, baik yang bersumber dari sampel maupun dari alat uji yang digunakan. Sumber ketidakpastian tersebut dapat dianalisa menggunakan diagram fishbone seperti Gambar 1. Sumber ketidakpastian dibagi menjadi sumber ketidakpastian $A$ dan sumber ketidakpastian B. Sumber ketidakpastian A diperoleh dari perulangan pengukuran dimensi sampel yaitu tebal penampang, lebar penampang dan pengujian tarik untuk mendapatkan nilai gaya tarik. Nilai tebal dan lebar sampel dapat dilihat pada Tabel 1, selain itu hasil pengukuran yang berupa nilai gaya tarik serta perhitungan nilai kekuatan tarik dapat dilihat pada tabel yang sama. Ketidakpastian B diperoleh dari kalibrasi alat uji tarik UTM dan alat ukur dimensi yang digunakan, dalam hal ini adalah micrometer. Nilai ketidakpastian ini diperoleh dari sertifikat kalibrasi alat dan dapat dilihat pada Tabel 3.

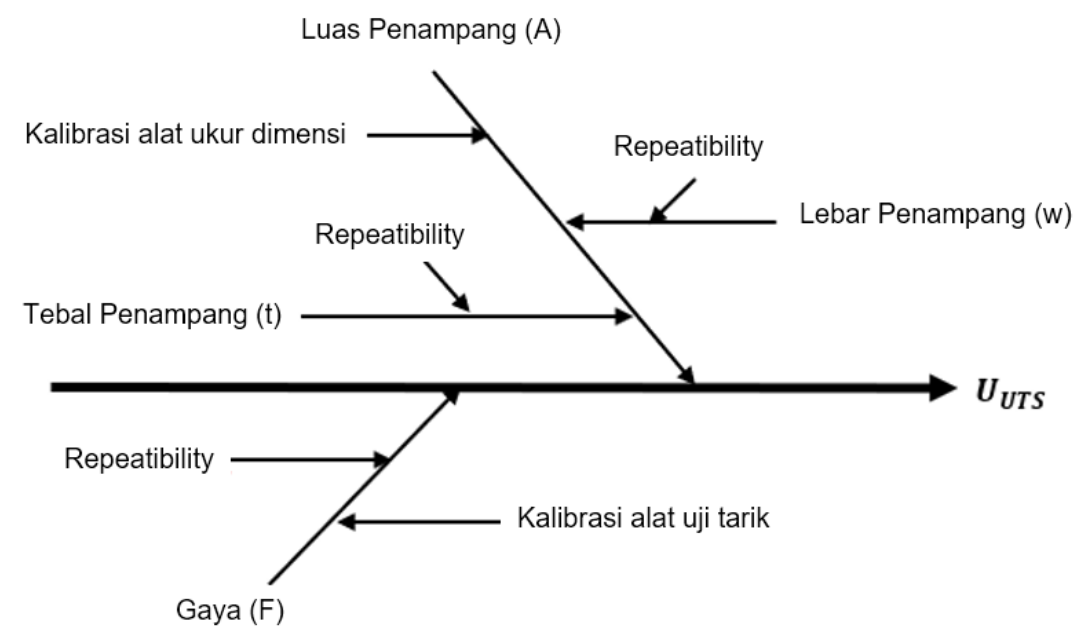

Gambar 1. Diagram fishbone ketidakpastian kekuatan tarik atau $U_{U T S}$.

Tabel 1. Data tebal, lebar, gaya dan kekuatan tarik spesimen.

\begin{tabular}{ccccc}
\hline No Sampel & Tebal $(\mathrm{mm})$ & Lebar $(\mathrm{mm})$ & Gaya $(\mathrm{N})$ & $\begin{array}{c}\text { Kekuatan Tarik } \\
\text { Maksimum (N.mm-2) }\end{array}$ \\
\hline 1 & 0,857 & 4,080 & 4304,869 & 615,826 \\
2 & 0,817 & 4,607 & 4953,346 & 658,320 \\
3 & 0,803 & 4,043 & 4346,459 & 669,068 \\
4 & 0,810 & 4,510 & 4555,942 & 623,572 \\
5 & 0,810 & 4,520 & 4730,676 & 646,055 \\
6 & 0,850 & 4,740 & 4874,932 & 604,980 \\
7 & 0,863 & 4,870 & 5042,527 & 599,668 \\
\hline Rata-rata & 0,830 & 4,481 & 4686,964 & 631,070 \\
\hline
\end{tabular}

Ketidakpastian keberulangan dari pengukuran atau ketidakpastian standar ditentukan berdasarkan standar deviasi dengan menggunakan persamaan 1 , sedangkan standar deviasi dihitung dengan menggunakan persamaan 2 .

$$
\begin{aligned}
& u(x)=\frac{s}{\sqrt{ } n} \\
& s=\sqrt{\frac{\sum_{n-1}^{n}(x-\bar{x})^{2}}{n-1}}
\end{aligned}
$$


Dengan $\mathrm{u}(\mathrm{x})$, ketidakpastian standar dari parameter; s, standar deviasi sampel; $\mathrm{n}$, jumlah sampel; x, nilai parameter (tebal, lebar, gaya, kekuatan tarik maksimum) dari sampel; $\bar{x}$, nilai rata-rata parameter. Nilai standar deviasi dan ketidakpastian standar dapat dilihat pada Tabel 2.

Tabel 2. Nilai standar deviasi dan ketidakpastian standar setiap parameter.

\begin{tabular}{lrr}
\hline Parameter & Standar Deviasi & Ketidakpastian Standar \\
\hline Tebal $(\mathrm{mm})$ & 0,026 & 0,010 \\
Lebar $(\mathrm{mm})$ & 0,313 & 0,118 \\
Gaya $(\mathrm{mm})$ & 292,613 & 110,597 \\
Kekuatan Tarik Maksimum $\left(\mathrm{Nmm}^{-2}\right)$ & 26,976 & 10,196 \\
\hline
\end{tabular}

Nilai ketidakpastian peralatan diperoleh dari sertifikat yang didalamnya dicantumkan ketidakpastian diperluas dan faktor cakupan. Ketidakpastian standar ditentukan dari ketidakpastian diperluas dibagi dengan faktor cakupannya. Persamaan ketidakpastian standar yang berasal dari sertifikat kalibrasi ditentukan dengan menggunakan persamaan
3. Dengan $u(e)$, ketidakpastian standar alat (micrometer atau universal testing machine); $U(e)$, ketidakpastian diperluas; $K$, factor cakupan.

$u(e)=\frac{U(e)}{K}$

Tabel 3. Nilai ketidakpastian standar dari alat.

\begin{tabular}{ccc}
\hline Parameter & Ketidakpastian diperluas & Ketidakpastian Standar \\
\hline Micrometer $(\mathrm{mm})$ & 0,020 & 0,010 \\
UTM, tension & 1,172 & 2,343 \\
\hline
\end{tabular}

Kekuatan tarik sampel berbentuk ring diperoleh dari gaya tarik dibagi dengan 2 kali luas area penampang ring dan secara matematis dapat dilihat pada persamaan 4, oleh karena itu koefisien sensitivitas dapat ditentukan dengan menurunkan persamaan kekuatan tarik terhadap parameter penyumbang ketidakpastian seperti pada persamaan 5 untuk parameter tebal, persamaan 6 untuk parameter lebar dan persamaan 7 untuk parameter gaya. Koefisien sensitivitas dari alat diperoleh dengan menggunakan persamaan 8. Hasil perhitungan koefisien sensitivitas dapat dilihat pada Tabel 4.

$$
\begin{aligned}
& \bar{\sigma}=\frac{\bar{F}}{2 \bar{A}}=\frac{\bar{F}}{2 \bar{t} \bar{w}} \\
& c_{t}=\frac{\partial \bar{\sigma}}{\partial \bar{t}}=-\frac{\bar{F}}{2 \bar{w} \bar{t}^{2}} \\
& c_{w}=\frac{\partial \bar{\sigma}}{\partial \bar{w}}=-\frac{\bar{F}}{2 \bar{w}^{2} \bar{t}} \\
& c_{F}=\frac{\partial \bar{\sigma}}{\partial \bar{F}}=\frac{1}{2 \bar{w} \bar{t}} \\
& c_{e}=\frac{\partial y}{\partial x}
\end{aligned}
$$

Dengan $\bar{\sigma}$, kekuatan tarik rata-rata $\left(\mathrm{Nmm}^{-2}\right) ; \bar{F}$, gaya rata-rata yang diserap bahan $(\mathrm{N}) ; A$, luas penampang rata-rata benda uji $\left(\mathrm{mm}^{2}\right) ; \bar{t}$, tebal rata-rata benda uji $(\mathrm{mm}) ; \bar{w}$, lebar rata-rata benda uji $(\mathrm{mm})$; $\mathrm{c}_{t}$, nilai koefisien sensitivitas dari tebal sampel $\left(\mathrm{Nmm}^{-3}\right) ; \mathrm{C}_{\mathrm{w}}$, nilai koefisien sensitivitas dari lebar sampel $\left(\mathrm{Nmm}^{-3}\right) ; \mathrm{CF}$, nilai koefisien sensitivitas dari gaya tarik sampel $\left(\mathrm{mm}^{-2}\right)$; $\mathrm{C}_{\mathrm{e}}$, nilai koefisien sensitivitas dari peralatan micrometer atau UTM.

Koefisien sensitivitas memberikan skala fungsi pembobot untuk setiap komponen ketidakpastian. Hal ini dapat menjelaskan terjadinya variasi kontribusi ketidakpastian karena perubahan input parameter. Koefisien sensitivitas mempunyai andil dalam evaluasi kontribusi ketidakpastian karena menjadi faktor pengali untuk menyamakan satuannya. Kontribusi ketidakpastian setiap parameter adalah ketidakpastian standar dikalikan dengan koefisien sensitivitasnya, dan hasilnya seperti pada kolom 3, Tabel 4. Kontribusi ketidakpastian yang paling besar adalah dari pengukuran lebar, hal ini terjadi karena sampel yang digunakan berasal dari pemotongan yang berbeda. Dari 7 sampel kemungkinan keberulangan pemotongannya tidak seragam sehingga lebar yang dihasilkan 
bervariasi. Penyumbang ketidakpastian terbesar kedua adalah dari keberulangan pengujian tarik dan dapat dipastikan bahwa alat uji telah dikalibrasi tetapi sampel yang berbeda penangannya akan menghasilkan nilai yang berbeda, sehingga dari 7 sampel diperoleh kontribusi perulangannya sebesar $14,867 \mathrm{Nmm}^{-2}$.

Tabel 4. Nilai koefisien sensitivitas, kontribusi ketidakpastian dan derajat kebebasan dari setiap parameter.

\begin{tabular}{lccc}
\hline Parameter & $\begin{array}{c}\text { Koefisien Sensitivitas } \\
\left(\mathrm{Nmm}^{-3}\right)\end{array}$ & $\begin{array}{c}\text { Kontribusi Ketidakpastian } \\
\left(\mathrm{Nmm}^{-2}\right)\end{array}$ & Derajat Kebebasan \\
\hline Tebal & $-759,083$ & $-7,325$ & 6 \\
Lebar & $-140,589$ & $-16,648$ & 6 \\
Gaya & 0,134 & 14,867 & 6 \\
Micrometer & 1,000 & 0,010 & $10^{13}$ \\
UTM, tension & 1,000 & 1,172 & $10^{13}$ \\
\hline
\end{tabular}

Ketidakpastian gabungan diperoleh dengan mengakarkuadratkan penjumlahan kuadrat nilai kontribusi ketidakpastian setiap parameter seperti pada persamaan 9, sedangkan ketidakpastian diperluas adalah ketidakpastian gabungan dikalikan factor cakupan seperti pada persamaan 10 pada tingkat kepercayaan 95\%. Dengan menggunakan tabel-t [12] dapat ditentukan factor cakupan dari nilai ketidakpastian yang telah dianalisa, tetapi untuk dapat menggunakan tabel-t terlebih dahulu ditentukan nilai derajat kebebasan efektif menggunakan persamaan 11 , hasilnya dapat dilihat pada tabel 5. Derajat kebebasan efektif ini ditentukan dari derajat kebebasan kontribusi ketidakpastian masing-masing parameter, hal ini ditentukan dengan menggunakan persamaan 12 untuk parameter tebal, lebar dan gaya. Sedangkan untuk derajat kebebasan parameter yang berasal dari kalibrasi ditentukan sebesar $10^{13}$ [7] dan hasilnya dapat dilihat pada Tabel 4.

$$
\begin{aligned}
u_{c \sigma} & =\sqrt{\left(u_{t} \cdot c_{t}\right)^{2}+\left(u_{w} \cdot c_{w}\right)^{2}+\left(u_{F} \cdot c_{F}\right)^{2}+\left(u_{m} \cdot c_{m}\right)^{2}+\left(u_{U T M} \cdot c_{U T M}\right)^{2}} \\
U_{\sigma} & =k \cdot u_{c \sigma} \\
V_{e f f} & =\frac{u_{c \sigma}{ }^{4}}{\sum \frac{u_{p}{ }^{4}}{v_{p}}} \\
v_{p} & =n-1
\end{aligned}
$$

Dengan $u_{c \sigma}$, ketidakpastian gabungan kekuatan tarik; $u_{t}$, ketidakpastian standar parameter tebal; $u_{w}$, ketidakpastian standar parameter lebar; $u_{F}$, ketidakpastian standar parameter gaya; $u_{m}$, ketidakpastian standar alat micrometer; $u_{U T M}$, ketidakpastian standar alat UTM; $U_{\sigma}$, ketidakpastian diperluas; k, factor cakupan; $V_{\text {eff }}$, derajat kebebasan efektif; $v_{p}$, derajat kebebasan parameter (tebal, lebar, gaya).

Tabel 5. Nilai ketidakpastian gabungan dan ketidakpastian diperluas.

\begin{tabular}{cccc}
\hline $\begin{array}{c}\text { Ketidakpastian Gabungan } \\
\left(\mathrm{Nmm}^{-2}\right)\end{array}$ & $\begin{array}{c}\text { Derajat Kebebasan } \\
\text { Efektif }\end{array}$ & $\begin{array}{c}\text { Faktor } \\
\text { Cakupan }\end{array}$ & $\begin{array}{c}\text { Ketidakpastian Diperluas } \\
\left(\mathrm{Nmm}^{-2}\right)\end{array}$ \\
\hline 23,520 & 14,285 & 2,145 & 50,451 \\
\hline
\end{tabular}

Analisa ketidakpastian terhadap pengujian kekuatan tarik berbentuk ring menghasilkan nilai sebesar $50,451 \mathrm{Nmm}^{-2}$, hal ini dikarenakan preparasi 7 buah sampel yang menghasilkan lebar dengan standar deviasi $6,985 \%$, begitu pula dengan pengulangan pengukuran gaya menghasilkan standar deviasi $6,243 \%$. Penyumbang ketidakpastian pengukuran kekuatan tarik berasal dari pengukuran lebar dan gaya.

\section{b. Analisa Ketidakpastian Elongasi}

Seperti pada analisa ketidakpastian kekuatan tarik, sumber ketidakpastian perubahan panjang terhadap panjang awal atau elongasi dapat dikategorikan menjadi 
ketidakpastian A dan B. Kategori A bersumber dari perulangan pengukuran dimensi dan ketegori B adalah berasal dari sertifikat alat ukur micrometer. Uraian tersebut dapat dilihat pada diagram fishbone gambar 2. Nilai pengukuran panjang awal dan panjang akhir dapat dilihat pada tabel 6. Dari hasil pengukuran tersebut dapat ditentukan nilai elongasi dari perubahan struktur material akibat pengujian tarik.

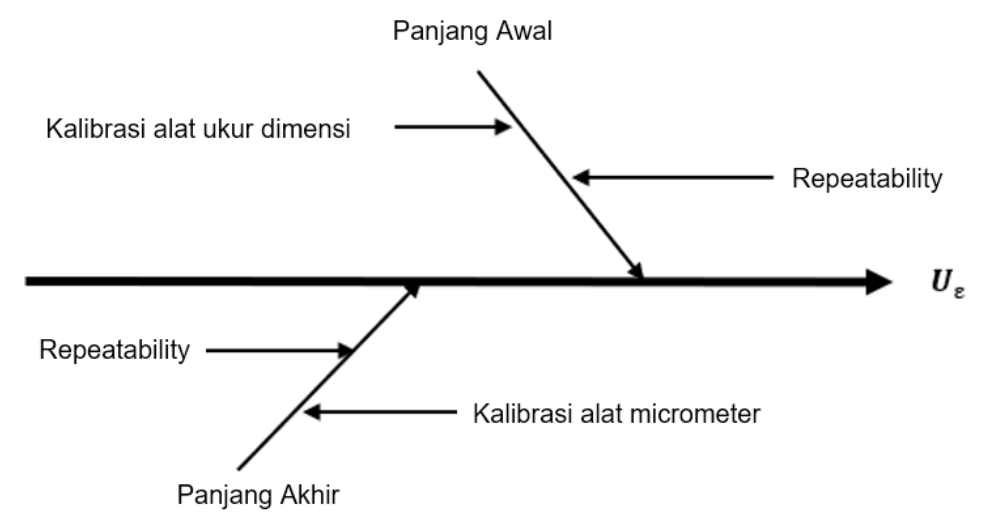

Gambar 2. Diagram fishbone ketidakpastian elongasi $\left(u_{\varepsilon}\right)$.

Tabel 6. Data panjang awal, panjang akhir dan elongasi.

\begin{tabular}{ccccc}
\hline No Sampel & $\begin{array}{c}\text { Panjang Awal } \\
(\mathrm{mm})\end{array}$ & $\begin{array}{c}\text { Panjang Akhir } \\
(\mathrm{mm})\end{array}$ & $\begin{array}{c}\text { Perubahan Panjang } \\
(\mathrm{mm})\end{array}$ & $\begin{array}{c}\text { Elongasi } \\
(\%)\end{array}$ \\
\hline 1 & 88,289 & 71,082 & 17,207 & 19,490 \\
2 & 87,965 & 71,052 & 16,913 & 19,227 \\
3 & 88,059 & 68,545 & 19,514 & 22,160 \\
4 & 88,143 & 71,864 & 16,279 & 18,469 \\
5 & 87,912 & 72,491 & 15,421 & 17,542 \\
6 & 87,504 & 75,066 & 12,438 & 14,214 \\
7 & 88,017 & 70,732 & 17,285 & 19,638 \\
\hline Rata-rata & 87,984 & 71,547 & 16,437 & 18,681 \\
\hline Standar Deviasi & 2,162 & 2,425 & 2,425 & 2,425 \\
\hline
\end{tabular}

Berdasarkan nilai pengukuran maka ditentukan nilai standar deviasi menggunakan persamaan 2 dan ketidakpastian standar menggunakan persamaan 1. Ketidakpastian alat ukur micrometer sama dengan nilai ketidakpastian micrometer pada analisis ketidakpastian kekuatan tarik, karena menggunakan alat yang sama. Hasil penentuan standar deviasi dapat dilihat pada tabel 6 , dan hasil ketidakpastian standar dari masing-masing parameter dapat dilihat pada tabel 7.

Tabel 7. Data ketidakpastian standar panjang awal, panjang akhir dan micrometer.

\begin{tabular}{lc}
\hline Parameter & Ketidakpastian Standar \\
\hline Lo $_{0}(\mathrm{~mm})$ & 0,817 \\
$\mathrm{~L}_{1}(\mathrm{~mm})$ & 0,916 \\
Micrometer $(\mathrm{mm})$ & 0,010 \\
\hline
\end{tabular}

Elongasi diperoleh dari perubahan panjang terhadap panjang awal seperti persamaan 13 , dengan demikian koefisien sensitivitas parameter penyumbang ketidakpastian diperoleh dari menurunkan persamaan elongasi terhadap panjang awal (persamaan 14) dan terhadap panjang akhir (persamaan 15). Hasi penentuan koefisien sensitivitas dapat dilihat pada tabel 8 . Dengan diperolehnya niali sensitivitas maka dapat ditentukan kontribusi ketidakpastian masingmasing parameter yaitu nilai ketidakpastian standar dikalikan dengan koefisien sensitivitasnya, hasilnya seperti ditunjukkan 
pada Tabel 8. Ketidakpastian gabungan elongasi dapat ditentukan dengan menggunakan persamaan 16 dan hasilnya dapat dilihat pada tabel 9 . Untuk menentukan ketidakpastian diperluas terlebih dahulu dilakukan penentuan derajat kebebasan dari parameter panjang awal dan panjang akhir dengan menggunakan persamaan 12 serta derajat kebebasan kalibrasi micrometer

$\varepsilon=\frac{\overline{\Delta L}}{\overline{L_{0}}} 100 \%=\frac{\left(\overline{L_{1}}-\overline{L_{0}}\right)}{\overline{L_{0}}} \times 100 \%$

$c_{L_{1}}=\frac{\partial \bar{\varepsilon}}{\partial \bar{L}_{1}}=\frac{1}{\overline{L_{1}}} x 100 \%$

$c_{L_{0}}=\frac{\partial \bar{\varepsilon}}{\partial \bar{L}_{0}}=-\frac{L_{1}}{L_{0}^{2}} \times 100 \%$

$u_{c \varepsilon}=\sqrt{\left(u_{L_{1}} \cdot c_{L_{1}}\right)^{2}+\left(u_{L_{0}} \cdot c_{L_{0}}\right)^{2}+\left(u_{m} \cdot c_{m}\right)^{2}}$

$V_{e f f}=\frac{u_{c \varepsilon}{ }^{4}}{\sum \frac{u_{p}^{4}}{v_{p}}}$

Dengan $\varepsilon$, elongasi; $\overline{\Delta L}$, rata-rata perubahan panjang; $\overline{L_{1}}$, rata-rata panjang akhir; $\overline{L_{0}}$, ratarata panjang awal; $c_{L_{1}}$, koefisien sensitivitas panjang akhir; $c_{L_{0}}$, koefisien sensitivitas panjang awal; $u_{c \varepsilon}$, ketidakpastian gabungan elongasi; $u_{L_{1}}$, ketidakpastian parameter ditentukan sebesar $10^{13}$ [7]. Setelah diperoleh derajat kebebasan masing-masing parameter kemudian ditentukan derajat kebebasan efektif menggunakan persamaan 17. Nilai derajat kebebasan efektif digunakan untuk menentukan faktor cakupan dengan tingkat kepercayaan $95 \%$ pada tabel-t dan hasilnya dapat dilihat pada tabel 9. Persamaan elongasi $(\varepsilon)$ adalah:

panjang akhir; $u_{L_{0}}$, ketidakpastian parameter panjang awal; $u_{m}$, ketidakpastian parameter micrometer; $V_{\text {eff, }}$ derajat kebebasan efektif; $v_{p}$, derajat kebebasan parameter (panjang awal, panjang akhir).

Tabel 8. Data ketidakpastian standar panjang awal, panjang akhir dan micrometer.

\begin{tabular}{cccc}
\hline Parameter & $\begin{array}{c}\text { Koefisien Sensitivitas } \\
\left(\mathrm{mm}^{-1}\right)\end{array}$ & Kontribusi Ketidakpastian & Derajat Kebebasan \\
\hline Panjang awal & $-0,924 \%$ & $-0,755 \%$ & 6 \\
Panjang akhir & $1,137 \%$ & $1,042 \%$ & 6 \\
Micrometer & $1,000 \%$ & $0,010 \%$ & $10^{13}$ \\
\hline
\end{tabular}

Tabel 9. Data ketidakpastian standar panjang awal, panjang akhir dan micrometer.

\begin{tabular}{cccc}
\hline $\begin{array}{c}\text { Ketidakpastian Gabungan } \\
(\%)\end{array}$ & $\begin{array}{c}\text { Derajat Kebebasan } \\
\text { Efektif }\end{array}$ & $\begin{array}{c}\text { Faktor } \\
\text { Cakupan }\end{array}$ & $\begin{array}{c}\text { Ketidakpastian Diperluas } \\
(\%)\end{array}$ \\
\hline 1,287 & 10,964 & 2,228 & 2,867 \\
\hline
\end{tabular}

Nilai ketidakpastian perubahan panjang terbesar diperoleh dari kontribusi pengukuran panjang akhir sebesar $1,042 \%$ karena variasi dari hasil ukur yang ditunjukkan dengan standar deviasi 2,425 mm. Dari analisa ketidakpastian ini diperoleh ketidakpastian diperluas sebesar $2,867 \%$ dengan tingkat kepercayaan $95 \%$ dan factor cakupan 2,228.

\section{SIMPULAN}

Dari pengujian yang dilakukan dapat diketahui bahwa kekuatan tarik ring SS304 rata-rata adalah $631,070 \pm 26,976 \mathrm{Nmm}^{-2}$ dengan ketidakpastian diperluas sebesar $50,451 \mathrm{Nmm}^{-2}$ pada tingkat kepercayaan $95 \%$. Selain itu pada tingkat kepercayaan yang sama diperoleh hasil elongasi ring SS304 rata-rata $18,681 \% \pm 2,425 \%$ dengan ketidakpastian diperluas sebesar 2,867\%. Keberulangan data atau repeatability menjadi penyumbang terbesar terhadap ketidakpastian pengukuran kekuatan tarik dan elongasi ring SS304. 


\section{UCAPAN TERIMA KASIH}

Penulis mengucapkan terima kasih kepada PTBBN yang telah membiayai penelitian ini melalui DIPA PTBBN Tahun Anggaran 2021.

\section{DAFTAR PUSTAKA}

[1]. ISO, "Evaluation of measurement data - Guide to the expression of uncertainty in measurement," Int. Organ. Stand. Geneva ISBN, vol. 50, no. September, p. 134, 2008, [Online]. Available:

http://www.bipm.org/en/publications/gui des/gum.html.

[2]. JGCM, "Supplement 1 to the "Guide to the Expression of Uncertainty in Measurement" - Propagation of distributions using a Monte Carlo method, JCGM 101:2008," Int. Organ. Stand. Geneva ISBN, 2008.

[3]. JCGM, "JCGM 102 : 2011 Evaluation of measurement data - Supplement 2 to the 'Guide to the expression of uncertainty in measurement' Extension to any number of output quantities," Jcgm, vol. 102, no. October, pp. 1-72, 2011.

[4]. Komite Akreditasi Nasional, "Pedoman Evaluasi dan Pelaporan Ketidakpastian Pengukuran," 2003.

[5]. A. Chen and C. Chen, "Comparison of GUM and Monte Carlo methods for evaluating measurement uncertainty of perspiration measurement systems," Meas. J. Int. Meas. Confed., vol. 87, pp. 27-37, 2016, doi: 10.1016/j.measurement.2016.03.007.

[6]. B. Salah, Z. Slimane, M. Zoheir, and B. Jurgen, "Uncertainty estimation of mechanical testing properties using sensitivity analysis and stochastic modelling," Meas. J. Int. Meas. Confed., vol. 62, pp. 149-154, 2015, doi: 10.1016/j.measurement.2014.10.036.

[7]. A. Shamsuri, M. Awing, and M. Tawil, "Calculation of measurement uncertainty for tensile strength and flexural strength of thermoplastic," Asian Res. J. Math., vol. 1, no. 3, pp. 1-11, 2016, doi: 10.9734/arjom/2016/28947.

[8]. T. Yoshitake, Y. Abe, N. Akasaka, S. Ohtsuka, S. Ukai, and A. Kimura, "Ringtensile properties of irradiated oxide dispersion strengthened ferritic /martensitic steel claddings," J. Nucl. Mater., vol. 329-333, no. 1-3 PART A, pp. 342-346, 2004, doi: 10.1016/j.jnucmat.2004.04.084.

[9]. F. Nagase, T. Sugiyama, and T. Fuketa, "Optimized ring tensile test method and hydrogen effect on mechanical properties of zircaloy cladding in hoop direction," J. Nucl. Sci. Technol., vol. 46, no. 6, pp. 545-552, 2009, doi: 10.1080/18811248.2007.9711560.

[10]. J. Yoon, J. Kim, H. Kim, C. Won, Y. Song, and S. H. Park, "Calibration of hoop stress in ring tensile test with Zircaloy-4 tube," J. Mech. Sci. Technol., vol. 31, no. 9, pp. 4183-4188, 2017, doi: 10.1007/s12206-017-0815-8.

[11]. J. Setiawan, Sungkono, "Karakteristik daktilitas SS304 yang teroksidasi pada suhu tinggi," Jurnal Daur Bahan Bakar Nuklir Urania, vol 23, no.3, hal. 165174, 2017.

[12]. Junaidi, "Titik Persentase Distribusi T," 2010. https://repository.unja.ac.id/209/ 1/tabel-t.pdf. 
